\title{
Pengaruh Metode Koagulasi, Sedimentasi dan Variasi Filtrasi terhadap Penurunan Kadar TSS, COD dan Warna pada Limbah Cair Batik
}

\author{
Rahmah $^{1, *}$, Surahma Asti Mulasari ${ }^{2}$ \\ ${ }^{\mathbf{1 , 2}}$ Fakultas Kesehatan Masyarakat, Universitas Ahmad Dahlan \\ *email: Rahmasti_fkmuad@yahoo.com
}

\begin{abstract}
Batik industry in Indonesia increased, so that the impact result from the production process in the form of wastewater is increasing. Wastewater disposal after staining and washing process without processing will improve environmental contamination suchas TSS, COD and color levels. The problems of batik wastewater contamination can be resolved by treatment of wastewater in chemistry and physics. One way batik wastewater treatment are coagulation, sedimentation and filtration. Filtration media are used as filter media is activated charcoal, quartz sand and zeolite. The purpose of this research to determine the effect of coagulation, sedimentation and filtration variation method to decreased levels of TSS, COD and color in the wastewater of batik. The type of this research was a true experiment with pretest post-test group design. Samples of this research were batik wastewater with levels of TSS, COD and color are $818 \mathrm{mg} / \mathrm{l}, 1133,57 \mathrm{mg} / \mathrm{l}$ and $100 \mathrm{TCU}$. Data analyzed using one-way ANOVA. The result after treatment of coagulation, sedimentation and filtration variety occurs decreased levels of TSS, COD and color on filtration variation of activated charcoal and quartz sand, respectively for 99,8\%, $99,49 \%$ and $99,6 \%$, variation of the zeolite filtration and activated charcoal was, 99,6\%, 92,31\% and $99,5 \%$, and variations in zeolite filtration and quartz sand was 99,7\%, 89,92\% and 99,3\%. Based on the statistical test using ANOVA test on the TSS levels were obtained $p=0,190$, while the COD were obtained value of $p=0,008$ and the value of color was $p=0,017$. The methods of coagulation, sedimentation and filtration variation using activated charcoal, quartz sand and zeolite can reduce TSS, COD and color levels. There is no difference between the variation of filtration to decrease levels of TSS, while there is a difference between the variation filtration to decreased levels of effluent COD and color Batik.
\end{abstract}

Keywords: coagulation, sedimentation, filtration variation, TSS, COD, color

\section{Pendahuluan}

Peningkatan volume usaha industri batik tidak sejalan dengan pengetahuan para pengrajin untuk mengolah limbah yang dihasilkan pada proses akhir industri. Jumlah limbah yang dihasilkan meningkat sehingga dapat merusak, mencemari lingkungan dan membahayakan kesehatan manusia [1]. Penggunaan bahan kimia biasanya pada saat proses pewarnaan maupun pencelupan kain batik. Keberadaan polutan yang terdapat pada limbah cair industri batik ini dapat berupa padatan tersuspensi, bahan kimia maupun zat

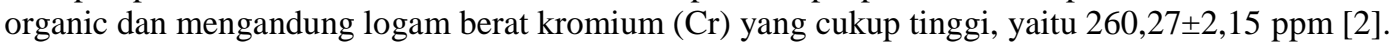

Kadar ini sudah melebihi ambang batas logam berat, yaitu hanya sebesar 1 ppm. Pembuangan limbah cair industri batik biasanya memiliki konsentrasi logam berat yang melebihi baku mutu yang telah ditetapkan oleh pemerintah. Oleh karena itu, pengolahan limbah cair industri batik perlu diterapkan, sebab jika limbah langsung dibuang ke badan air penerima maupun lingkungan, maka penurunan kualitas lingkungan dan kerusakan ekosistem sekitar industri batik tidak dapat dihindari [2].

Limbah bahan berbahaya dan beracun adalah sisa usaha dan/atau kegiatan yang mengandung bahan berbahaya dan/ atau beracun yang karena sifat dan/ atau konsentrasinya dan/atau jumlahnya, baik secara langsung maupun tidak langsung, dapat mencemarkan dan/ atau merusakkan lingkungan hidup, dan/ atau dapat membahayakan lingkungan hidup, kesehatan, kelangsungan hidup manusia serta makhluk hidup lain [3]. Pembuangan limbah cair setelah proses pewarnaan dan pencucian tanpa pengolahan akan mempengaruhi kandungan oksigen dalam air, meningkatnya BOD, COD, TSS, phenol, dan ikut pula mempengaruhi pH air lingkungan [4].

Pengolahan air limbah secara umum terbagi menjadi 3 teknik pengolahan, yaitu pengolahan secara fisika, kimia dan biologi [5]. Pengolahan secara fisika pada umumnya dilakukan untuk pemisahan bahan cemaran dalam air limbah dengan penyaringan. Sebelum dilakukan proses filtrasi dilakukan proses 
sedimentasi yaitu proses pengendapan bahan padat dari air olahan. Proses sedimentasi adalah pemisahan bagian padat dengan memanfaatkan gaya gravitasi sehingga bagian yang padat berada di dasar kolam pengendapan, sedangkan air murni berada di atas. Untuk mempercepat proses pengendapan perlu ditambahkan bahan koagulan seperti tawas agar terbentuk flock yang dapat mengendap dan kapur agar tercipta suasana basa pada air limbah. Air olahan yang akan disaring berupa cairan mengandung butiran halus atau bahan-bahan yang terlarut. Dengan demikian, bahan-bahan tersebut dapat dipisahkan dari cairan melalui filtrasi [6].

Media filtrasi sangat diperlukan untuk mendukung kelancaran proses pengolahan air dan dapat menyerap ion-ion dalam air sehingga air dapat menjadi jernih dan bebas dari unsur pencemar. Media pengolahan pada air biasanya menggunakan karbon aktif, batu kerikil, sedangkan untuk padatan yang halus dapat menggunakan pasir sebagai media penyaring [7]. Arang aktif merupakan suatu bentuk karbon yang mempunyai sifat absorptiv terhadap larutan ataupun uap sehingga bahan tersebut dapat berfungsi sebagai penjernih larutan, penghisap gas/ racun dan penghilang warna [8]. Pasir kuarsa juga sering digunakan untuk pengolahan air. Fungsi ini baik untuk menghilangkan sifat fisiknya, seperti kekeruhan atau lumpur dan bau. Selain itu, zeolit juga merupakan bahan penyaring air yang banyak digunakan, karena memiliki pori-pori berukuran molekuler sehingga mampu memisahkan/ menyaring molekul dengan ukuran tertentu [7].

Persyaratan menurut Peraturan Gubernur Kepala Daerah Istimewa Yogyakarta Nomor 7 Tahun 2010 tentang Baku Mutu Limbah Cair bagi Kegiatan Industri, bahwa parameter TSS, COD dan warna harus memenuhi baku mutu yang telah ditetapkan. Parameter TSS limbah cair batik yang diperbolehkan adalah 200 $\mathrm{mg} / \mathrm{L}$, parameter COD limbah cair batik yang diperbolehkan adalah $100 \mathrm{mg} / \mathrm{L}$, sehingga untuk memenuhi baku mutu yang sudah ditetapkan perlu adanya pengolahan limbah yaitu dengan pengolahan secara kimia dan biologi.

Berdasarkan uraian di atas maka peneliti tertarik untuk melakukan penelitian dengan menggunakan metode koagulasi, sedimentasi dan variasi filtrasi menggunakan arang aktif, pasir kuarsa dan zeolit untuk menurunkan kadar TSS, COD, dan warna dalam limbah cair batik.

\section{Metode}

Jenis penelitian ini adalah true experiment dengan pre test post test group design. Penelitian ini digunakan untuk mengetahui pengaruh metode koagulasi, sedimentasi dan variasi filtrasi terhadap penurunan kadar TSS, COD dan warna pada limbah cair batik. Penelitian ini dilaksanakan pada bulan Januari-Februari tahun 2015. Obyek penelitian ini adalah seluruh limbah cair industri batik di Yogyakarta. Sampel penelitian ini adalah limbah cair batik di salah satu home industri di Yogyakarta. Analisis data menggunakan analisis one way anova, untuk mengetahui perbedaan perlakuan variasi filtrasi terhadap penurunan kadar TSS, COD dan warna pada limbah cair batik.

\section{Hasil Penelitian dan Pembahasan}

\section{Hasil Penelitian}

\section{Pengolahan metode koagulasi, sedimentasi dan variasi filtrasi}

Penelitian ini dilaksanakan pada tanggal 24-30 Januari 2015, penelitian ini bertujuan untuk mengetahui penurunan kadar TSS, COD dan warna serta pengaruh metode koagulasi, sedimentasi dan variasi filtrasi dengan berbagai variasi media filtrasi. Variasi media filtrasi yang digunakan yaitu kombinasi arang aktif dan pasir kuarsa, zeolit dan arang aktif serta zeolit dengan pasir kuarsa. Rangkaian yang digunakan yaitu alat pengolahan limbah yang terbuat dari ember dengan ukuran tinggi $39 \mathrm{~cm}$ dan diameter $30 \mathrm{~cm}$ digunakan untuk proses koagulasi dan sedimentasi, serta media penyaring yang sudah dibuat dengan diameter pipa PVC $10 \mathrm{~cm}$ dan ketinggian $100 \mathrm{~cm}$. Pada proses koagulasi digunakan bahan koagulan tawas dengan dosis $10 \mathrm{~g} / \mathrm{l}$ dan kapur $25 \mathrm{~g} / \mathrm{l}$ dan waktu pengadukan cepat selama 1 menit dan pengadukan selama 10 menit, serta proses sedimentasi dilakukan selama 3 jam untuk mengendapkan larutan dengan air baku. Pada proses filtrasi digunakan variasi media arang aktif, pasir kuarsa dan zeolit dengan ketebalan masingmasing media $40 \mathrm{~cm}$ dan ketebalan media setiap masing-masing tabung $80 \mathrm{~cm}$. Proses penyaringan dilakukan selama 45 menit. Pengolahan limbah cair batik dilakukan pengulangan sebanyak 3 kali pada setiap variasi media saring yang sama, kemudian diambil air sampel pada masing-masing tabung penyaring untuk diperiksa sebagai post test (setelah perlakuan) di Balai Laboratorium Kesehatan.

\section{Penurunan kadar TSS, COD dan Warna}

Penurunan kadar TSS, COD dan warna pada limbah cair batik setelah dilakukan pengolahan dengan metode koagulasi, sedimentasi dan variasi filtrasi dengan media filtrasi arang aktif, pasir kuarsa 
dan pasir kuarsa. Adapun hasil pemeriksaan kadar TSS, COD dan warna limbah cair batik setelah pengolahan dapat dilihat pada tabel berikut:

Tabel 1. Hasil pemeriksaan kadar TSS, COD dan warna limbah cair batik setelah pengolahan metode koagulasi, sedimentasi dan variasi filtrasi dengan media filtrasi arang aktif, pasir kuarsa dan zeolite

\begin{tabular}{ccccccc}
\hline Variasi & \multicolumn{5}{c}{ Parameter } \\
\cline { 2 - 7 } Filtrasi & \multicolumn{2}{c}{ TSS } & \multicolumn{2}{c}{ COD } & \multicolumn{2}{c}{ Wama } \\
\cline { 2 - 7 } & Hasil & $\%$ & Hasil & $\%$ & Hasil & $\%$ \\
\hline A & 11195,3 & $99,8 \%$ & 9222,77 & $99,49 \%$ & 10463,3 & $99,6 \%$ \\
B & 11183,6 & $99,6 \%$ & 8597,68 & $92,31 \%$ & 10456,6 & $99,5 \%$ \\
C & 11176,1 & $99,7 \%$ & 8391,04 & 89,92 & 10436,6 & $99,3 \%$ \\
\hline
\end{tabular}

Tabel 1. menunjukan bahwa hasil pengolahan koagulasi, sedimentasi dan variasi filtrasi terjadi penurunan paling tinggi pada kadar TSS, COD dan warna terjadi pada variasi filtrasi arang aktif dan pasir kuarsa berturut-turut sebesar $99,8 \%, 99,49 \%$ dan $99,6 \%$, dan terjadi penurunan paling rendah pada variasi filtrasi zeolit dan pasir kuarsa sebesar 99,7\%, 89,92\% dan 99,3\%, dengan demikian dapat disimpulkan bahwa pada variasi filtrasi arang aktif dan pasir kuarsa paling tinggi dalam menurunkan kadar TSS, COD dan warna.

\section{Perbedaan perlakuan variasi filtrasi terhadap penurunan kadar TSS, COD dan warna}

Perbedaan perlakuan variasi filtrasi terhadap penurunan kadar TSS, COD dan warna dilakukan uji anova. Adapun hasil uji anova berdasarkan variasi filtrasi media penyaring arang aktif dan pasir kuarsa, zeolit dan arang aktif serta zeolit dan pasir kuarsa terhadap penurunan TSS, COD danwarna ditunjukan pada tabel berikut:

Tabel 2. Hasil uji anova berdasarkan variasi filtrasi dengan media penyaring arang aktif dan pasir kuarsa, zeolit dan arang aktif, serta zeolit dan pasir kuarsa terhadap penurunan kadar TSS, COD dan warna limbah cair batik

\begin{tabular}{ccc}
\hline Parameter & P-Value & Perbedaan signifikan \\
\hline TSS & 0,190 & Tidak ada \\
COD & 0,008 & Ada \\
Wama & 0,017 & Ada \\
\hline
\end{tabular}

Tabel 2 menunjukan bahwa berdasarkan analisis uji anova bahwa untuk melihat perbedaan antara variasi filtrasi dengan penurunan kadar TSS, COD dan warna dapat dilakukan dengan melihat nilai p-value. Pada penurunan kadar TSS nilai $\mathrm{p}=0,190$ sehingga $\mathrm{p}$-value $>\alpha(0,05)$, maka Ho diterima, atau tidak ada perbedaan yang signifikan antara variasi filtrasi terhadap penurunan kadar TSS limbah cair batik. Nilai p-value kadar COD yaitu $\mathrm{p}=\mathrm{n} 0,008$, sehingga $\mathrm{p}$-value $<\alpha(0,05)$ yang berarti Ho ditolak, atau ada beda yang signifikan antara variasi media filtrasi terhadap penurunan kadar COD limbah cair batik. Nilai $\mathrm{p}$-value pada warna yaitu $\mathrm{p}=\mathrm{n} 0,017$ sehingga $\mathrm{p}$ - value $<\alpha(0,05)$ yang berarti Ho ditolak, atau ada beda yang signifikan antara variasi media filtrasi terhadap penurunan warna limbah cair batik.

\section{Kelompok variasi filtrasi yang paling tinggi dalam menurunkan kadar TSS, COD dan warna}

Hasil uji post hoc untuk mengetahui variasi filtrasi yang paling tinggi dalam menurunkan kadar TSS, COD dan warna ditunjukan pada tabel berikut: 
Tabel 3. Hasil uji Post Hoc antara kelompok variasi filtrasi media penyaring arang aktif dan pasir kuarsa, zeolit dan arang aktif, serta zeolit dan pasir kuarsa terhadap penurunan kadar TSS, COD dan warna limbah cair batik

\begin{tabular}{cccc}
\hline Parameter & Variasi & P-Value & Perbedaan Signifikan \\
\hline TSS & Xa dan Xb & 0,251 & Tidak ada \\
& Xa dan Xc & 0,082 & Tidak ada \\
& Xb dan Xc & 0,445 & Tidak ada \\
COD & Xa dan Xb & 0,012 & Ada \\
& Xa dan Xc & 0,003 & Ada \\
Wama & Xb dan Xc & 0,285 & Tidak ada \\
& Xa dan Xb & 0,356 & Tidak ada \\
& Xa dan Xc & 0,007 & Ada \\
& Xb dan Xc & 0,024 & Ada \\
\hline
\end{tabular}

Tabel 3 menunjukan bahwa berdasarkan hasil uji post hoc untuk melihat variasi filtrasi yang paling tinggi dalam menurunkan kadar TSS, COD dan warna dapat dilakukan dengan melihat nilai p-value. Pada kadar TSS nilai $\mathrm{p}$-value pada variasi $\mathrm{Xa}$ dan $\mathrm{Xb} \mathrm{p}=0,251$, Xa dan $\mathrm{Xc} \mathrm{p}=0,082$ dan $\mathrm{Xb}$ dan $\mathrm{Xc} \mathrm{p}=$ 0,445 sehingga $\mathrm{p}>\alpha(0,05)$, berarti secara statistik tidak ada perbedaan yang signifikan antara kelompok variasi filtrasi terhadap penurunan kadar TSS. Pada kadar COD, variasi Xa dan Xb didapatkan $\mathrm{p}=0,012$, variasi $\mathrm{Xa}$ dan $\mathrm{Xc} p=0,003$ sehinggan $\mathrm{p}<\alpha(0,005)$, berarti ada perbedaan yang signifikan antara kelompok variasi fitrasi terhadap penurunan kadar COD, sedangkan variasi Xb dan Xc didapatkan nilai $\mathrm{p}=0,285$ sehingga $\mathrm{p}>\alpha 0,05$, berarti tidak ada perbedaan yang signifikan antara kelompok varaisi filtrasi terhadap penurunan kadar COD. Pada warna, variasi Xa dan Xb didapatkan nilai $\mathrm{p}=0,356$ sehingga $\mathrm{p}>\alpha 0,05$, berarti tidak ada perbedaan yang signifikan antara kelompok variasi filtrasi terhadap penurunan warna, sedangkan variasi $\mathrm{Xa}$ dan $\mathrm{Xb}$ nilai $\mathrm{p}=0,007$ dan variasi $\mathrm{Xb}$ dan $\mathrm{Xc} \mathrm{p}=$ 0,024 sehingga $\mathrm{p}<\alpha 0,05$, berarti ada perbedaan yang signifikan antara kelompok variasi filtrasi terhadap penurunan warna.

\section{Pembahasan}

Hasil penelitian menunjukan bahwa variasi filtrasi arang aktif dan pasir kuarsa paling tinggi dalam menurunkan kadar TSS, COD dan warna. Metode koagulasi dan sedimentasi merupakan metode yang sangat berperan dalam menurunkan kadar TSS. Proses koagulasi akan mengalami pembentukan flok pada limbah cair batik dan proses sedimentasi untuk memisahkan endapan dengan air olahan.

Setelah pemisahan endapan, air olahan disaring dengan menggunakan media filtrasi arang aktif, pasir kuarsa dan zeolit. Pada proses filtrasi, variasi yang paling tinggi menurunkan kadar TSS, COD dan warna adalah variasi arang aktif dan pasir kuarsa, karena arang aktif mempunyai sifat adsorbtif sehingga media filtrasi berfungsi sebagai penjernih larutan, penghisap gas/ racun dan penyerap warna. Selain itu arang aktif mempunyai suatu gaya gabung dengan bahan organik, hal tersebut dapat digunakan untuk meremoval bahan kontaminan organik dari air limbah terutama kadar COD.

Penelitian lain menyatakan bahwa pemanfaatan arang aktif limbah kulit kacang kedelai mempunyai pengaruh aktif dalam meningkatkan kualitas limbah cair tahu. Hasil menunjukkan perlakuan terbaik, yaitu pada berat 3 gram dengan penurunan kadar COD menjadi $3260 \mathrm{mg} / \mathrm{l}$, penurunan kadar BOD menjadi 768 $\mathrm{mg} / \mathrm{l}$, dan $\mathrm{pH}$ meningkat menjadi 5,3 [9]. Penelitian lain menyatakan bahwa arang limbah kayu ulin mempengaruhi terhadap limbah cair sasirangan yang diolah secara filtrasi. Hal ini ditunjukkan dengan penurunan kadar COD sampai 81,358 \% yang merupakan ukuran yang maksimum merurunkan kadar COD [10].

Penelitian lain menyatakan bahwa media filtrasi arang aktif dan pasir kuarsa dapat menurunkan kadar TSS, COD dan warna berturut-turut sebesar $84,4 \%$, 80,7\% dan 86,8\%, dengan ketebalan media filter $80 \mathrm{~cm} .9$ Penelitian lain menyatakan bahwa penggunaan arang aktif sebagai adsorben dapat menurunkan kadar COD sebesar 68\% dengan dosis karbon aktif sebanyak 4 gram [11].

Berdasarkan hasil uji statistik menunjukan bahwa pada kadar TSS tidak ada perbedaan yang signifikan antara variasi filtrasi terhadap penurunan kadar TSS limbah cair batik (P 0,190). Kadar COD ada perbedaan yang signifikan antara variasi media filtrasi terhadap penurunan kadar COD limbah cair batik (P 0,008), dan pada warna ada perbedaan yang signifikan antara variasi media filtrasi terhadap penurunan warna limbah cair batik (0,017).

Berdasarkan uji statistik menunjukan bahwa pada kadar kadar TSS nilai p-value pada variasi Xa dan Xb $p=0,251, X a$ dan $X c p=0,082$ dan $X b$ dan $X c p=0,445$ sehingga $p>\alpha(0,05)$, berarti secara statistik tidak ada 
perbedaan yang signifikan antara kelompok variasi filtrasi terhadap penurunan kadar TSS. Pada kadar COD, variasi $\mathrm{Xa}$ dan $\mathrm{Xb}$ didapatkan $\mathrm{p}=0,012$, variasi $\mathrm{Xa}$ dan $\mathrm{Xc} p=0,003$ sehinggan $\mathrm{p}<\alpha(0,005)$, berarti ada perbedaan yang signifikan antara kelompok variasi fitrasi terhadap penurunan kadar COD, sedangkan variasi $\mathrm{Xb}$ dan $\mathrm{Xc}$ didapatkan nilai $\mathrm{p}=0,285$ sehingga $\mathrm{p}>\alpha 0,05$, berarti tidak ada perbedaan yang signifikan antara kelompok varaisi filtrasi terhadap penurunan kadar COD. Pada warna, variasi $\mathrm{Xa}$ dan $\mathrm{Xb}$ didapatkan nilai $\mathrm{p}=$ 0,356 sehingga $p>\alpha 0,05$, berarti tidak ada perbedaan yang signifikan antara kelompok variasi filtrasi terhadap penurunan warna, sedangkan variasi $\mathrm{Xa}$ dan $\mathrm{Xb}$ nilai $\mathrm{p}=0,007$ dan variasi $\mathrm{Xb}$ dan $\mathrm{Xc} \mathrm{p}=0,024$ sehingga $\mathrm{p}<\alpha 0,05$, berarti ada perbedaan yang signifikan antara kelompok variasi filtrasi terhadap penurunan warna. Namun secara biologis atau deskriptif ada perbedaan antara kelompok variasi filtrasi dengan media arang aktif dengan pasir kuarsa, zeolit dengan arang aktif dan zeolit dengan pasir kuarsa.

Dari ketiga variasi filtrasi, penurunan kadar parameter TSS, COD dan warna yang sesuai dengan baku mutu yang telah ditetapkan oleh Peraturan Gubernur Kepala Daerah Istimewa Yogyakarta Nomor 7 Tahun 2010 yaitu variasi filtrasi arang aktif dan pasir. Penelitian lain menyatakan bahwa mengkombinasikan penggunaan karbon aktif dan pasir aktif dengan tinggi tumpukan $80 \mathrm{~cm}$ dan waktu perendaman 45 menit, diperoleh hasil pengolahan limbah yang memenuhi persyaratan baku mutu, yaitu dapat menurunkan kadar TSS, COD dan warna berturut-turut sebesar 84,4\%, 80,7\% dan 86,8\% [12]. Penelitian lain menyatakan bahwa penggunaan arang aktif dapat menurunkan warna sebesar 99,98\%, dengan menggunakan mesh 80 dari limbah gergaji kayu jati [13]. Air limbah yang telah diadsorpsi dengan menggunakan arang aktif dan pasir kuarsa dapat menurunkan kadar COD pada air limbah, karena arang aktif mempunyai gaya gabung dengan bahan organik dari air limbah terutama kadar COD, kadar COD dalam air limbah akan berkurang seiring dengan berkurangnya konsentrasi bahan organik yang terdapat dalam air limbah. Penelitian lain menyatakan bahwa penggunaan arang aktif sebagai adsorben dapat menurunkan kadar COD sebesar $68 \%$ dengan dosis karbon aktif sebanyak 4 gram [11].

\section{Kesimpulan dan Saran}

\section{Kesimpulan}

1. Metode koagulasi, sedimentasi dan variasi filtrasi sebagai metode pengolahan limbah cair batik dapat menurunkan kadar TSS pada limbah cair batik, dengan variasi filtrasi A dapat menurunkan TSS sebesar 99,8\%, variasi filtrasi B sebesar 99,6\%, dan variasi filtrasi C sebesar 99,7\%.

2. Metode koagulasi, sedimentasi dan variasi filtrasi sebagai metode pengolahan limbah cair batik dapat menurunkan kadar COD pada limbah cair batik, dengan variasi filtrasi A dapat menurunkan COD sebesar 99,49\%, variasi filtrasi B sebesar 92,31\%, dan variasi filtrasi C sebesar 89,92\%.

3. Metode koagulasi, sedimentasi dan variasi filtrasi sebagai metode pengolahan limbah cair batik dapat menurunkan kadar warna pada limbah cair batik, dengan variasi filtrasi A dapat menurunkan warna sebesar 99,6\%, variasi filtrasi B sebesar 99,5\%, dan variasi filtrasi C sebesar $99,3 \%$.

4. Tidak ada perbedaan pengaruh pengolahan metode koagulasi, sedimentasi dan variasi filtrasi arang aktif dengan zeolit, zeolit dengan arang aktif dan zeolit dengan pasir kuarsa terhadap penurunan TSS pada limbah cair batik. Ada perbedaan pengaruh pengolahan metode koagulasi, sedimentasi dan variasi filtrasi arang aktif dengan zeolit, zeolit dengan arang aktif dan zeolit dengan pasir kuarsa terhadap penurunan COD pada limbah cair batik. Ada perbedaan pengaruh pengolahan metode koagulasi, sedimentasi dan variasi filtrasi arang aktif dengan zeolit, zeolit dengan arang aktif dan zeolit dengan pasir kuarsa terhadap penurunan warna pada limbah cair batik.

\section{Saran}

1. Pengolahan dengan metode koagulasi, sedimentasi dan variasi filtrasi menggunakan media arang aktif, pasir kuarsa dan zeolit dapat digunakan sebagai salah satu cara dalam menurunkan kadar TSS, COD dan warna pada limbah cair batik pada home industry batik.

2. Perlu dilakukan penelitian mencoba menggunakan metode koagulasi, sedimentasi dan variasi filtrasi untuk menurunkan parameter lain, seperti BOD, $\mathrm{pH}$, TDS, dan bahan logam yang terkandung dalam limbah cair batik.

3. Perlu mencoba melakukan penelitian pengaruh lama waktu pengendapan dan penyaringan media saring arang aktif, pasir kuarsa dan zeolit untuk penurunan kadar TSS, COD dan warna.

4. Perlu melakukan penelitian pengolahan limbah batik dengan penambahan metode aerasi untuk menurunkan kadar COD sesuai dengan baku mutu.

5. Perlu dilakukan penelitian pengolahan lumpur hasil endapan dari metode koagulasi dan sedimentasi dengan pengolahan secara biologi. 


\section{Daftar Pustaka}

[1] Dewi, L., Santini, P., 2013, "Elektrodekolorisasi Limbah Cair Zat Warna Batik Dengan Elektroda $\mathrm{PbO}_{2} / \mathrm{Pb}$ ", Chem Info, 1 (1), hal. 1-6.

[2] Sari, A., Rachmadiarti, F., Fitrihidayati, H., 2014, Pengaruh Cekaman Kromium Pada Limbah Cair Batik Terhadap Pertumbuhan Eichornia Crassipes Dan Salvinia molesta, Lentera Bio, 3 (1), hal. 76-71.

[3] Undang-Undang Republik Indonesia Nomor 23 Tahun 1997 Tentang Pengelolaan Lingkungan Hidup.

[4] Wardana, W.A., 2004, Dampak Pencemaran Lingkungan. Andi Offset, Yogyakarta

[5] Rachman, C. Musanif, J., Sulaeman, D., 2009, Pedoman Desain Teknik IPAL Agroindustri, Direktorat Pengolahan Hasil Pertanian, Direktorat Jendral Pengolahan dan Pemasaran Hasil Pertanian, Departemen Pertanian, Hal : 19.

[6] Asmadi, Suharno, 2012, Dasar-Dasar Teknologi Pengolahan Air Limbah, Gosyen Publishing, Yogyakarta, Hal: 14-164.

[7] Sudrajat, R., 1985, "Pengaruh Beberapa Faktor Terhadap Sifat Arang Aktif”, Jurnal Penelitian Hasil Hutan.Vol. 2 No.2.

[8] Kusnaedi, 2010, Mengolah Air Kotor untuk Air Minum, Penebar Swadaya, Jakarta, Hal: 25-41.

[9] Laras, N., Yuliani, Fitrihidajati, H., 2015, "Pemanfaatan Arang Aktif Limbah Kulit Kacang Kedelai (Glycine max) Dalam Meningkatkan Kualitas Limbah Cair Tahu”, LenteraBio, 4 (1), hal. 72-76.

[10] Utami, U., Nurmasari, R., 2007, "Pengolahan Limbah Cair Sasirangan Secara Filtasi Melalui Pemanfaatan Arang Kayu Ulin Sebagai Adsorben”, Jurnal Sains MIPA, 13 (3), hal. 190-196.

[11] Kasam, Andik, Y., Titin, S., 2005, "Penurunan COD (Chemical Oxygen Demand) dalam Limbah Cair Laboratorium Menggunakan Filter Karbon Aktif Arang Tempurung Kelapa", LOGIKA, Vol. 2, No. 2, ISSN 1410-2315, 3-17.

[12] Sumarni, 2012, "Adsorpsi Zat Warna Dan Zat Padat Tersuspensi Dalam Limbah Cair Baik", Prosiding Seminar Nasional Aplikasi Sains \& Teknologi (SNAST) Periode III ISSN: 1979911XYogyakarta, 3 November 201, 263-269.

[13] Sudarja., dan Caroko., 2012, "Kaji Experimental Efektifitas Penyerapan Limbah Cair Industri Batik Taman Sari Yogyakarta Menggunakan Arang Aktif Mesh 80 dari Limbah Gergaji Kayu Jati”, Jurnal Ilmiah Semesta Teknika, Vol. 14, No. 1, 50-58. 